\title{
The Effects of Stroke Patients` Physical Functions and Emotional Characteristics on their Quality of Life
}

\author{
Sung-Hee Lee ${ }^{1}$, Sea-Hyun Bae ${ }^{2}$ Jin-A Hwang ${ }^{2}$ and Kyung-Yoon Kim ${ }^{2}$ \\ ${ }^{1}$ Department of Occupational Therapy, Chonnam National University Bitgoeul \\ Hospital, Gwangju, Korea \\ ${ }^{2}$ Department. of Physical Therapy, Dongshin University, Naju, Korea \\ Ifirstot@naver.com, ${ }^{2}$ qbseadp@daum.net, ${ }^{2}$ hwangxena@naver.com \\ ${ }^{2}$ redbead7@daum.net
}

\begin{abstract}
This study analyzed stroke patients' physical functional degree, acceptance of disability, and coping methods and examined the effect of such factors on their quality of life. With stroke patients whose mini-mental state Examination-Korean score was 24 points or higher as subjects, their general characteristics, physical functions, acceptance of disability, coping strategies, and quality of life were measured. In order to look at differences in their quality of life according to physical functions and emotional characteristics, an independent t-test and one-way analysis of variance were conducted. Pearson correlation analysis was conducted to examine relationship between the patients' physical functions, emotional characteristics, and quality of life and a stepwise multiple regression analysis was carried out in order to look at their effects on the patients' quality of life. There was significant difference ( $p<0.001)$ according to stroke patients' physical functions, acceptance of disability, and coping measures. Physical functional disorder $(r=-.23)$ had negative correlation with their quality of life and acceptance of disability $(r=.54)$ and coping strategies $(r=.22)$ had significant positive correlation with their quality of life. The higher the degree of stroke patients' physical disability, the lower their quality of life and the higher their acceptance of disability and coping degree, the higher their quality of life. When rehabilitation treatment is done, a comprehensive approach is needed considering social and emotional characteristics such as acceptance of disability and coping strategies.
\end{abstract}

Keywords: Stoke, Physical function, Emotional characteristics, Quality of life

\section{Introduction}

After a stroke, about half the survivors come to have disabilities of some level and in many cases they depend on their family members or others for activities of daily living [1]. As a result, they come to face psycho-social difficulties such as changes into a dependent life style, passive health management, loss of their roles, decreased self-esteem, and reduced self-efficacy, with degraded quality of life [2].

Most stroke patients find it hard to accommodate sudden physical changes and functional disabilities and fail to adapt to a changed environment [3]. A stroke negatively affects their physical functional level and cognitive functions [4] with difficulty with rehabilitation process. In addition, acceptance of disability is the process of adapting to disabilities and an essential element for the disabled's psycho-social adaptation and an important and a vital factor affecting their quality of life [5]. A high level of acceptance of disability may lead to a positive sense of self and make adaptation to ordinary life and vocational life easy [6]. Although there remains a sense of loss resulting from disability, values for remaining ability are accepted positively [7]. On the other hand, those with a low level of acceptance of disability come to have negative perception [8]. Like this, 
acceptance of disability is an essential stage for health management and psycho-social adaptation [9] and it can be guessed that the issue of acceptance of disability is important for rehabilitation process.

Stroke patients undergo internal stress from disability and external stress such as changes in their role in their family and fear for interpersonal relationship [10]. When they think they can change stress with such stress coping strategies, they opt for problemfocused coping and when they think they cannot, they use emotion-focused coping [11]. Stress coping strategies greatly affect their quality of life [12].

The quality of life is the ultimate goal for health related interventions and therefore the quality of life is very important for chronic patients. Therefore, if treatment goals are set by analyzing factors affecting their quality of life, it will be able to positively influence their rehabilitation motives and quality of life [13]. Although acceptance of disability and coping strategies faced by stroke patients in their recovery process are variables that may affect their different aspects of life, research on their quality of life in comprehensive consideration of such factors is still insufficient.

Accordingly, this study analyzed stroke patients' physical functional disability, acceptance of disability, which is an emotional characteristic, and coping methods, and examined their relationship with their quality of life, aiming to provide basic data as an intervention measure for improving stroke patients' quality of life.

\section{Subjects and Methods}

\subsection{Subjects}

The subjects of this study were patients who received rehabilitation after diagnosed with a stroke. The subject was able to communicate and respond to the questionnaire. Their mini-mental state Examination-Korean(MMSE-K) score was 24 points or higher and they had no history of mental disease such as schizophrenia, manic depression, and symptoms of organic psychosis.

\subsection{Study Procedures}

This study obtained approval from the H University's Institutional Review Board and data collection was conducted in a total of 18 institutions including eight general hospitals located in Gyeonggi-do, Chungcheong-do, and Geolla-do, four convalescent hospitals, and six clinics. For the survey, a total of 280 questionnaires were distributed and 240 questionnaires were collected. Among them, 36 questionnaires with insincere answers were excluded and a total of 204 questionnaires (85\%) were ultimately analyzed.

\subsection{Study Tools}

2.3.1. Physical Functional Level" In order to evaluate stroke patients' disability level and functional conditions, a Modified Rankin Scale (MRS) was used. In this study, zero to two points were mild state, three to six points were moderate to severe state (Table 1).

Table 1. Modified Rankin Scale

\begin{tabular}{c|l}
\hline Score & \multicolumn{1}{c}{ Content } \\
\hline 0 & The patient has no symptoms \\
\hline 1 & $\begin{array}{l}\text { There are symptoms without disability and the patient may perform all } \\
\text { activities of daily living. }\end{array}$ \\
\hline 2 & $\begin{array}{l}\text { The patient has slight disability and may perform tasks for himself or herself } \\
\text { but has difficulty with performing all prior activities }\end{array}$ \\
\hline
\end{tabular}




\begin{tabular}{c|l}
\hline 3 & $\begin{array}{l}\text { The patient has moderate disability and may walk without help but needs } \\
\text { slight assistance. }\end{array}$ \\
\hline 4 & $\begin{array}{l}\text { The patient has moderate to severe disability and may not do activities or } \\
\text { walk without help from others. }\end{array}$ \\
\hline 5 & $\begin{array}{l}\text { The patient has severe disability and needs continuous care and support } \\
\text { lying in a bed. }\end{array}$ \\
\hline 6 & The patient is dead with no functional state. \\
\hline
\end{tabular}

2.3.2. Acceptance of Liability: Acceptance of disability scale-9 is composed of three factors (self-satisfaction, not considering disability unique, and the quality of compensatory actions) and a total of nine questions. The patient was evaluated using a five-point Likert scale; The higher the patient's score, the higher level of acceptance of disability the patient has. The data was sequenced, and using an interquartile range, the degrees of acceptance of disability were divided.

2.3.3 Coping: For evaluation of stress coping ability, brief coping orientation to problems experienced scale (brief COPE) was used. The brief COPE was comprised of a total of 14 items and 28 questions. The 14 items were divided into problem-focused coping (8 items) and emotion-focused coping ( 6 items). It is a four point Likert scale and the higher the score, the more stress coping mode is used. Based on the score obtained from each area, the coping mode was decided according to the degree of deviation from the average value.

2.3.4 Quality of Life: In order to measure the subjects' quality of life, a simple scale (World Health Organization Quality-of-Life scale, WHOQOL-BREF) was used. It was composed of four areas (physical health area, psychological area, social area, and environmental area) and 26 questions. It is a self-reporting scale in which the quality of life patients felt for the past two weeks was subjectively evaluated. It is a Likert 5-point scale and the higher the score, the higher their quality of life. The scores of the four areas were converted to four to 20 points according to the short form scoring method.

\subsection{Data Analysis}

Statistical Package for the Social Sciences (SPSS) 20.0 statistical program was used for analysis of collected data. Frequency analysis was performed on the general characteristics of the subjects and descriptive statistics was applied to physical functional disability, acceptance of disability, coping strategies, and the quality of life. In order to examine differences in their quality of life according to physical functional disability, acceptance of disability, and coping strategies, a t-test, and analysis of variance were utilized. In addition, in order to look at relationship between physical functions and social and emotional characteristics and their quality of life, a pearson correlation analysis was conducted. A statistical significance level was set at $\mathrm{p}=.05$.

\section{Subjects}

\subsection{General characteristics of the Subjects}

In their general characteristics, the rate of males (54.5\%) was higher than that of females, the rate of those whose age was between 40 and $59(52.9 \%)$ was highest, the rate of those who had religion (68.6\%) was higher than that of those who did not, the rate of middle school graduator or those who received lower level of education was highest at $37.3 \%$, the rate of those who were married $(66.7 \%)$ was higher than those who were not, the rate of nuclear family $(72.1 \%)$ was higher than other forms of family, the rate of guardians among the main care givers was highest at $39.2 \%$, and the rate of those whose 
level of monthly income was $1,000,000$ won or lower (44.1\%) was highest. As for characteristics related to diseases, the rate of those who had cerebral infarction was 55.9\%, the rate of those whose duration of a stroke was six months or shorter was $44.6 \%$ and 12 months or longer was $44.6 \%$, the rate of those whose paretic side was left was $49 \%$, and the rate of those who had comorbidities was higher at $93.3 \%$ than that of those who did not. Hypertension accounted for a large portion at $45.1 \%$ among their comorbidities (Table 2).

Table 2. Clinical Characteristics of the Subjects $(n=204)$

\begin{tabular}{|c|c|c|c|}
\hline Characteristics & & Subjects & $\%$ \\
\hline \multirow{2}{*}{ Gender } & Male & 111 & 54.4 \\
\hline & Female & 93 & 45.6 \\
\hline \multirow{3}{*}{ Age } & $\leq 39$ & 23 & 11.3 \\
\hline & $40 \sim 59$ & 108 & 52.9 \\
\hline & $\geq 60$ & 73 & 35.8 \\
\hline \multirow{2}{*}{ Religion } & Yes & 140 & 68.6 \\
\hline & No & 64 & 31.4 \\
\hline \multirow{2}{*}{ Job } & Present & 31 & 15.2 \\
\hline & Absent & 169 & 82.8 \\
\hline \multirow{3}{*}{ Education } & $<$ Middle school & 76 & 37.3 \\
\hline & $>$ High school & 66 & 32.4 \\
\hline & $>$ Graduation & 62 & 30.4 \\
\hline \multirow{4}{*}{ Marriage } & Single & 27 & 13.2 \\
\hline & Married & 136 & 66.7 \\
\hline & Widowed & 29 & 14.2 \\
\hline & Divorce/separation & 12 & 5.9 \\
\hline \multirow{3}{*}{ Type of family } & Living alone & 32 & 15.7 \\
\hline & Nuclear family & 147 & 72.1 \\
\hline & Large family & 25 & 12.3 \\
\hline \multirow{4}{*}{ Caregivers } & Spouse & 80 & 39.2 \\
\hline & Children & 25 & 12.3 \\
\hline & Brothers & 4 & 2.0 \\
\hline & Other & 53 & 26.0 \\
\hline \multirow{3}{*}{$\begin{array}{l}\text { Monthly income } \\
\text { (million won) }\end{array}$} & $\leq 1$ & 90 & 44.1 \\
\hline & $1 \sim 3$ & 74 & 36.3 \\
\hline & $\geq 3$ & 40 & 19.6 \\
\hline \multirow{3}{*}{ Diagnoses } & Cerebral infarction & 114 & 55.9 \\
\hline & Cerebral hemorrhage & 76 & 37.3 \\
\hline & Other & 14 & 6.9 \\
\hline \multirow{3}{*}{ Stroke duration(months) } & $\leq 6$ & 91 & 44.6 \\
\hline & $6 \sim 12$ & 22 & 10.8 \\
\hline & $\geq 12$ & 91 & 44.6 \\
\hline Disability types & Left hemiplegia & 100 & 49.0 \\
\hline
\end{tabular}




\begin{tabular}{lrrr}
\hline & Right hemiplegia & 86 & 42.2 \\
Bilateral hemiplegia & 18 & 8.8 \\
\hline Absent & 14 & 6.7 \\
Present & 190 & 93.3 \\
Language disorder & 22 & 10.8 \\
Dysphagia & 14 & 6.9 \\
Comorbidity & 39 & 19.1 \\
& Diabetes mellitus & 92 & 45.1 \\
Hypertension & 15 & 7.4 \\
Heart disease & 4 & 2.0 \\
Kidney disease & 4 & 2.0 \\
\hline
\end{tabular}

\subsection{The Subjects` Physical Functions, Emotional Characteristics and Quality of Life}

The score of their physical function measured by Modified Rankin Scale was an average of 2.64 .98 points and the number of those whose physical functions were mild was $96(47.1 \%)$ and whose physical functions were moderate to severe was 108 (52.9\%). The score of acceptance of disability was an average of $27.07 \pm 5.80$ points and the number of those whose acceptance of disability was high was 106 (52\%). To look at sub-areas, the quality of compensatory behaviors was $10.15 \pm 2.86$ points, the area of not considering disability unique was $8.64 \pm 03.34$ points, and the score of self-satisfaction was $8.27 \pm 2.54$ points.

As for the subjects' coping strategies, problem-focused coping was $41.33 \pm 1.00$ points (103 subjects, $50.5 \%$ ) and emotion-focused coping was $23.06 \pm 6.09$ points (101 patients, $49.5 \%)$. The score of their quality of life was high in the order of social relationship area $(11.91 \pm 4.21$ points), environmental area $(11.26 \pm 3.25$ points $)$, psychological area (11.26 \pm 3.17 points), and physical health area (10.06 \pm 2.84 points). Regarding the level of their quality of life, physical health area obtained the lowest score and the score of social relationship area was highest (Table 3).

Table 3. Physical Functions, Emotional Characteristics and Quality of life $(n=204)$

\begin{tabular}{llrr}
\hline Variables & Category & subject(\%) & \multicolumn{1}{c}{ M \pm SD } \\
\hline Physical ability & Mild & $96(47.1)$ & $1.73 \pm .05$ \\
& Moderate to severe & $108(52.9)$ & $3.45 \pm .05$ \\
& Total score & & $2.64 \pm .98$ \\
\hline Emotional characteristics & & & \\
Depression & No & $143(70.1)$ & $4.21 \pm 3.05$ \\
& Yes & $61(29.9)$ & $15.69 \pm 4.31$ \\
\cline { 2 - 3 } & Normal(0 4) & $76(37.3)$ & $1.77 \pm .17$ \\
& Mild(5 9) & $67(32.8)$ & $7.03 \pm .19$ \\
& Moderate(10 14) & $25(12.2)$ & $11.52 \pm .31$ \\
& Moderately severe & $25(12.3)$ & $16.92 \pm .30$ \\
& $(15 \sim 19)$ & $11(5.4)$ & $22.36 \pm .64$ \\
& Severe(20 27) & & $7.64 \pm 6.31$ \\
& Total & $98(48.0)$ & $22.40 \pm .35$
\end{tabular}




\begin{tabular}{|c|c|c|c|}
\hline & High & $106(52.0)$ & $31.40 \pm .38$ \\
\hline & Total & & $27.07 \pm 5.80$ \\
\hline & self-satisfaction & & $8.27 \pm 2.54$ \\
\hline & $\begin{array}{l}\text { De-emphasis on disability } \\
\text { salience }\end{array}$ & & $8.64 \pm 3.34$ \\
\hline & $\begin{array}{l}\text { compensatory behavioral } \\
\text { qualities }\end{array}$ & & $10.15 \pm 2.86$ \\
\hline \multirow[t]{3}{*}{ Coping Strategy } & Problem focused coping & $101(49.5)$ & $41.33 \pm 1.00$ \\
\hline & Emotional focused coping & $103(50.5)$ & $23.06 \pm 6.09$ \\
\hline & Total & & $64.39 \pm 2.11$ \\
\hline \multirow[t]{5}{*}{ Quality of Life } & Physical health & & $10.06 \pm 2.84$ \\
\hline & Psychological & & $11.26 \pm 3.17$ \\
\hline & Social relationships & & $11.91 \pm 4.21$ \\
\hline & Environment & & $11.26 \pm 3.25$ \\
\hline & Total & & $2.75 \pm 0.72$ \\
\hline
\end{tabular}

3.3. Differences in the Subjects`Quality of Life according to the Subjects` Physical Functions and Emotional Characteristics

3.3.1. Difference in their Quality of Life according to General Characteristics: There were statistically significant differences in their quality of life according to gender, educational level, and comorbidities among general characteristics. According to the posthoc test result, males' quality of life was higher than their female counterparts' and their quality of life was high in college graduators and those with no comorbidities (Table 4).

Table 4. Difference of Quality of life by General Characteristics $(n=204)$

\begin{tabular}{|c|c|c|c|}
\hline & & Quality of Life & \multirow{2}{*}{$t / F$} \\
\hline & & $\mathrm{M} \pm \mathrm{SD}$ & \\
\hline \multirow{2}{*}{ Gender } & Male & $67.78 \pm 16.84$ & \multirow{2}{*}{$2.307^{*}$} \\
\hline & Female & $62.80 \pm 15.05$ & \\
\hline \multirow[t]{3}{*}{ Age } & $\leq 39$ & $66.22 \pm 19.60$ & \multirow{3}{*}{.166} \\
\hline & $40 \sim 59$ & $66.29 \pm 15.44$ & \\
\hline & $\geq 60$ & $64.14 \pm 16.30$ & \\
\hline \multirow[t]{2}{*}{ Religion } & Yes & $62.08 \pm 14.09$ & \multirow{2}{*}{.001} \\
\hline & No & $65.67 \pm 15.81$ & \\
\hline \multirow[t]{2}{*}{ Job } & Present & $72.42 \pm 15.52$ & \multirow{2}{*}{1.775} \\
\hline & Absent & $64.55 \pm 16.06$ & \\
\hline \multirow[t]{3}{*}{ Education level } & $<$ middle school & $59.72 \pm 12.43$ & \multirow{3}{*}{$14.168^{* * * *}$} \\
\hline & $>$ high school & $63.59 \pm 15.38$ & \\
\hline & $>$ college & $74.65 \pm 17.36$ & \\
\hline \multirow[t]{4}{*}{ Marriage } & Single & $64.41 \pm 18.69$ & \multirow{4}{*}{1.228} \\
\hline & Married & $67.10 \pm 15.38$ & \\
\hline & Widowed & $58.45 \pm 16.10$ & \\
\hline & Divorce/separation & $67.00 \pm 17.07$ & \\
\hline
\end{tabular}




\begin{tabular}{llll} 
Type of family & Living alone & $60.19 \pm 17.59$ & \\
& Nuclear family & $67.15 \pm 16.12$ & 1.877 \\
& Large family & $62.68 \pm 13.38$ & \\
Caregivers & Spouse & $67.49 \pm 16.34$ & \\
& Children & $63.92 \pm 13.41$ & \\
& Brothers & $61.25 \pm 02.22$ & .926 \\
& Support workers & $62.05 \pm 16.13$ & \\
& Other & $66.23 \pm 17.83$ & \\
\hline Monthly income & $\leq 1$ & $61.96 \pm 15.61$ & \\
(million won) & $1 \sim 3$ & $66.84 \pm 15.78$ & 2.554 \\
& $\geq 3$ & $71.05 \pm 16.75$ & \\
\hline Diagnoses & Cerebral infarction & $64.84 \pm 16.81$ & \\
& Cerebral hemorrhage & $64.99 \pm 15.05$ & 2.163 \\
& Other & $75.85 \pm 14.79$ & \\
\hline Time since & $\leq 6$ & $63.45 \pm 15.53$ & \\
stroke(months) & $6 \sim 12$ & $62.27 \pm 13.58$ & 1.836 \\
& $\geq 12$ & $68.35 \pm 17.12$ & \\
\hline Disability types & Lleft hemiplegia & $65.79 \pm 14.74$ & \\
& Right hemiplegia & $64.69 \pm 17.89$ & .370 \\
& Bilateral hemiplegia & $68.06 \pm 15.99$ & \\
\hline Comorbidity & Absent & $68.95 \pm 17.02$ & $.012^{*}$ \\
& Present & $63.15 \pm 15.25$ & \\
\hline
\end{tabular}

$* \mathrm{p}<.05, * * \mathrm{p}<.01, * * * \mathrm{p}<.001$

3.3.2. Differences in the Subjects`Quality of Life According to Physical Functions: There was significant difference in their quality of life according to physical functions of stroke patients and those whose disability degree was mild had higher quality of life. As for emotional characteristics, there was significant difference in their quality of life in all depression, acceptance of disability, and coping strategies (Table 5).

Table 5. The Difference Quality of Life by Physical Functions and Emotional Characteristics

\begin{tabular}{llcc}
\hline Variables & & $\mathrm{M} \pm \mathrm{SD}$ & $\mathrm{t} / \mathrm{F}$ \\
\hline Physical ability & Mild & $2.92 \pm .69$ & \multirow{2}{*}{$3.179^{* * *}$} \\
& Moderate to severe & $2.60 \pm .72$ & \\
\hline Depression & Normal(0 4) & $3.22 \pm .532$ & \\
& Mild(5 9) & $2.62 \pm .624$ & \\
& Moderate(10 14) & $2.54 \pm .833$ & \multirow{2}{*}{$22.448^{* * *}$} \\
& Moderately severe(15 19) & $2.20 \pm .577$ & \\
& Severe(20 27) & $2.00 \pm .447$ & \\
Acceptance of disability & Low & $2.50 \pm .692$ & \multirow{2}{*}{$-5.016^{* * *}$} \\
& High & $2.98 \pm .676$ & \\
\hline Way of coping & Problem focused coping & $2.90 \pm .674$ & \multirow{2}{*}{$5.620^{* * *}$} \\
& Emotional focused coping & $2.27 \pm .676$ & \\
\hline
\end{tabular}

$* p<.05, * * p<.01, * * * p<.001$ 


\subsection{Association among the Subjects` Physical Functions, Social and Emotional Characteristics and their Quality of Life}

According to the result of conducting analysis of correlation among physical functions, social and emotional characteristics, and their quality of life, acceptance of disability had negative correlation with physical functions $(\mathrm{r}=-.194)$. Coping strategies did not have statistically significant correlation with physical functions $(r=-.090)$ and acceptance of disability $(\mathrm{r}=.126)$. The subjects' quality of life had negative correlation with their physical functions $(\mathrm{r}=-.278)$ and positive correlation with acceptance of disability $(\mathrm{r}=.526)$ and coping strategies $(\mathrm{r}=.214)$ (Table 6).

Table 6. The Correlations among Physical Dysfunction Depression, Acceptance of Disability, coping Strategy and Quality of Life

\begin{tabular}{lrrr}
\hline & Physical ability & $\begin{array}{l}\text { Acceptance of } \\
\text { disability }\end{array}$ & Way of coping \\
\hline Acceptance of disability & $-.194^{*}$ & & \\
Way of coping & -.090 & .126 & $.214^{* *}$ \\
Quality of life & $-.278^{* *}$ & $.526^{* *}$ & \\
\hline$* \mathrm{p}<.05, * * \mathrm{p}<.01, * * * \mathrm{p}<.001$ & & &
\end{tabular}

\section{Discussion}

This study was conducted in order to analyze characteristics of stroke patients' physical functions and acceptance of disability and coping strategies, which are their social and emotional traits, and examine their relationship, thereby figuring out which factors affected their quality of life.

Regarding the subjects' general characteristics, there was significant difference in their quality of life in gender, educational level, and comorbidities. Their quality of life was higher in males rather than females, those who graduated from college, and those who did not have comorbidities. In a study by Kim et al. (2007) [14], the quality of life in female patients was lower than that in male patients, which supported the result of the present study. Nonetheless, Ones et al. (2005) [15] reported that there was no difference in the subjects' quality of life between genders and Hopman and Verner (2003) [16] noted that in a follow up research after six months there was no difference in the subjects' quality of life between genders. Female stroke patients took responsibilities for a lot of portion of housekeeping activities according to patriarchal social structure and had a high possibility of having low economic capabilities $[17,18]$ and therefore their quality of life related to their health was low. You and Ahn (2009) [13] reported that the higher educational level, the higher the subjects' quality of life. Nonetheless, Suh and Choi (2010) noted that the higher educational level, the lower the subjects' quality of life and Seo et al. (2006) [20] observed that there was no difference in accordance with educational level, which were different from the result of the present study. Jang (2006) [21] observed that when the subjects' educational level was high, knowledge obtained through education affected their health management and therefore education was able to improve the quality of life related to health. There were significant differences in the subjects' quality of life according to comorbidities and research by Choi et al. (2004) [2] and Yang (2010) [22] supported the result of the present study. According to National Stroke Association (2009) [23], 1-4\% within one month after the onset of a stroke, 5-25\% within one year, and 20-40\% within five years underwent recurrence and Kim et al. (2012) [24] reported that patients' awareness of stroke was lacking. Measures to provide accurate information about stroke rehabilitation as well as to manage diabetes, hypertension, and cardiac diseases that 
require continuous management and control in addition to knowledge on stroke itself should be sought for.

Regarding physical functions of stroke patients, there were many patients $(52.9 \%)$ who had moderate to severe disability and correlation between physical functions and their quality of life was negative; The more severe physical function disability, the lower their quality of life. Park et al. (2011) [25] and Yang (2010) [22] reported that the fewer physical disabilities, the higher the patients' quality of life, verifying that there was correlation between the degree of functional disability and the patients' quality of life. On the other hand, Leger (2003) [26] and Hong et al. (1998) [27] reported that functional conditions did not significantly affect the patients' quality of life, which was not consistent with the result of the present study. The reason is that only physical functions themselves do not affect the patients' quality of life and physical functional disability affects other factors such as psychological and social domains, degrading their quality of life.

Acceptance of disability and coping strategies had positive correlation with the patients' quality of life. In a study by Park and Kim (2009) [28], acceptance of disability and the patients' degree of satisfaction with their life had high correlation, which was consistent with the result of the present study. Research on mentally retarded patients [29], research on the disabled's subjective quality of life [30], and research on senile stroke patients [22] all showed that acceptance of disability had significant influence on their quality of life. As for coping measures, emotion-focused coping (50.5\%) was more frequently used than problem-focused coping $(49.5 \%)$ and such coping measures affected the patients' quality of life. Jeong (2011) [31] observed that emotion-focused coping was more frequently used than problem-focused coping, supporting the present study result. Coping had no statistically significant correlation with physical functions and acceptance of disability. Ryu(2001) [32] noted that coping had negative correlation with depression and Jeong(2011) [31] observed that coping strategies had positive correlation with acceptance of disability, with different results from the present study result. Pakaenham(1999) [7] reported that the lower disability severity and the more frequently problem-focused measures were used, the higher the adaptation degree. Tak (1997) [33] noted that the more severe conflict, the higher the tendency to pursue evasive coping methods, one of emotional-focused coping strategies, and in the case of those who used evasive coping methods much, their mental-physical health level was low. Such result suggests that stroke patients' quality of life has been lowered and their coping strategies are a determinant factor [34] for their quality of life, although direct comparison is difficult because prior research on relationship between stroke patients' coping strategies and their quality of life is lacking. In the present study, coping failed to make significant explanation and therefore repetitive research is necessary.

This study examined the factors affecting stroke patients' quality of life and relationship between physical and emotional factors in order to provide basic data for high-quality rehabilitation treatment interventions after a stroke. To sum up the above study results, this study intends to make the following propositions.

Reduction of elements with negative influence on stroke patients' quality of life should be made by identifying psychological problems accepting disability as well as their improvement in physical disability. At an early stage after the occurrence of disability, stroke patients undergo negative emotions and have low level of acceptance of disability and high psychological discomfort [35]. Accordingly, psychological stages of acceptance of disability should be explained; it is one characteristic of psychological condition process and part of acceptance of disability process, thereby strengthening their active coping methods against stress. 


\section{Conclusions}

This study showed that the more severe physical disability, the lower the patients' quality of life, and the higher their acceptance of disability and coping strategies, the higher their quality of life and when physical disability was high, their acceptance of disability became low. In addition, their quality of life was affected most by acceptance of disability, followed by coping strategies, and physical functions. Stroke patients' degree of acceptance of disability and coping methods appearing in the process of adapting through rehabilitation were closely related over their life as a whole. Thus, stroke patients' emotional aspects as well as their physical functional disability should be considered together for rehabilitation treatment interventions and an approach with practical methods aimed at improving their acceptance of disability and coping strategies in consideration of individuals' characteristics is needed.

\section{References}

[1] J. Young and A. Forster, "Review of stroke rehabilitation", BMJ, vol. 334, (2007), pp. 86-90.

[2] S. A. Choi, S. W. Park, Y. N. Choi and S. J Jang, "Factors affecting health-related quality of life in chronic stroke patients", Korean J Stroke, vol. 6, no. 2, (2004), pp. 156-161.

[3] B. Billhart and K. Johnson, "Motivation and the coping process adults with disabilities: A qualitative Study". Rehabili Nurs, vol. 22, no. 5, (1997), pp. 249-256.

[4] P. L. Morris, B. Raphael and R. G. Robinson, "Clinical depression is associated with impaired recovery from stroke", Med J Aust, vol. 157, no. 4, (1992), p. 239-242.

[5] J. K. Park and J. J. Kim, "A study on the subjective quality of life of people with Disabilities", J Rehabil Resear, vol. 13, no. 1, (2009), pp. 163-186.

[6] S. H. Kim, "Effects of disability statues and attributional style on the disabiliity acceptance and depressive reaction", (Unpublished doctoral dissertation), (2000), Chugang University, Seoul.

[7] H. S. Kim, "The impacts of stroke patients' depression, motivation for rehabilitation and activities of daily living on quality of life", (Unpublished master's thesis), (2009), Hanyang University, Seoul.

[8] B. D. Gordy-McCready, "The efficacy and long term effects of participation in upward bound on quality of life", (Doctoral dissertation), (2001), University of Temple, Philadelphia.

[9] S. K. Park, "A study on factors influencing community integration of the disabled aborers from industrial accident”, J Soci Welf, vol. 22, no. 11, (1997), pp. 162-185.

[10] W. K. Park, "Perceive stress and depression in hemiplegia patients using neuman stressors concepts factors", (Master's thesis), (1988), Ewha Womans University, Seoul.

[11] R. A. Lazarus and S. Folkman, "Stress, Appraisal \& Coping", Springer Publishing Company, New York. (1984).

[12] S. H. Kim, S. S. Oh, E. H. Lee and H. J. Kim, "The chronic schizophrenic patient's quality of Life: Focused on stress coping strategy, symptom, and family support”, Korean Journal Clin Psych, vol. 24, no. 1, (2005), pp. 73-97.

[13] Y. Y. You and C. S. Ahn, "A study of the relationships between perceived rehabilitation motivation and quality of life in patients after a cerebrovascular accident", Journal Korean Soc Occup Ther, vol. 17, no. 2, (2009), pp. 1-16.

[14] W. O. Kim, H. S. Kang, M. J. Wang, J. H. Kim and J. Y. Choi, "Relationships among activity of daily living, depression, and quality of Life(QOL) in patients with stroke", Journal East-West Nurs Resear, vol. 13, no. 2, (2007), pp. 138-146.

[15] K. Ones, E. Yilmaz, B. Cetinkaya and N. Caglar, "Quality of life fo patients post stroke and the factors affecting It", Journal Stroke Cerebro Disea, vol. 14, no. 6, (2005), pp. 261-266.

[16] W. M. Hopman and J. Verner, "Quality of life during and after inpatient stroke rehabilitation", Stroke, vol. 34, (2003), pp. 801-805.

[17] J. Carod-Artal, J. A. Egido, J. L. Gonzalez and E. V. De Seijas, "Quality of life among stroke survivors evaluated 1 year after stroke: experience of a stroke unit”, Stroke, vol. 31, no. 2, (2000), pp. 2995-3000.

[18] J. Liang, "Sex differences in life satisfaction among the elderly", Journal Gerontol, vol. 37, no. 1, (1982), pp. 100-108.

[19] M. H. Suh and S. M. Choi-Kwon, "Structural equation modeling on quality of life in stroke survivors at 1 year after onset", Journal Korean Acad Nurs, vol. 20, no. 4, (2010), pp. 533-541.

[20] J. H Seo, J. Y. Kim, W. Y. Sung, H. J. Lim, J. W. Kim, S. Y. Kim and H. J. Jang, "A Study on relationship between the post-stroke depression and acceptance", J Orien Neuropsychi, vol. 17, no. 2, (2006), pp. 166-177.

[21] S. H. Jang, "A Study on the relationship between health status, social support and life satisfaction in elderly", Journal Korean Gernotol Nurs, vol. 8, no. 1, (2006), pp. 36-46. 
[22] J. B. Yang, "A study on the major factors affecting health-related quality of life of elderly stroke survivors", Journal Korean Gerontol Soc, vol. 30, no. 4, (2010), pp. 1027-1044.

[23] National Stroke Association, "Secondary stroke fact sheet", (http://www.stroke.org), (2009).

[24] Y. S. Kim, S. S. Park, H. J. Bae, J. H. Heo, S. U. Kwon, B. C. Lee, S. H. Lee, C. W. Oh and B. W. Yoon, "Public awareness of stroke in korea: a population-based national survey", Stroke, vol. 43, (2012), pp. 1146-1149.

[25] I. S. Park, D. Y. Kim and C. Y. Kang, "The Relationship of dysfunctions degree, daily living activity, depressiveness and quality of life among the elderly suffering from stroke", Korean Journal Health Serv Manage, vol. 5, no. 2, (2011), pp. 173-186.

[26] R. R. Leger, "The relationship among severity of illness, functional status and health-related quality of life in youth with spina bifida", (Unpublished doctoral dissertation), New York University, New York. (2003).

[27] Y. S. Hong, M. J. Suh, K. S. Kim, I. J. Kim, N. O. Cho, H. J. Choi, S. H. Jung and E. M. Kim, "Related factors of the quality of life in stroke patients", Korean J Rehab Nurs, vol. 1, no. 1, (1998), pp. 111-123.

[28] J. K. Park and J. J. Kim, "A study on the subjective quality of life of People with Disabilities", Journal Rehabil Resear, vol. 13, no. 1, (2009), pp. 163-186.

[29] S. H. Roh, "A study on constructing the model of the physical disabilities' subjective quality of life according to aging", (Doctoral dissertation), Soongsil University, Seoul, (2007).

[30] G. L. Albrecht and P. J. Devlieger, "The disability paradoox: high quality of life against all odds", Socl Scien and Medi, vol. 48, no. 8, (1999), pp. 977-988.

[31] H. M. Jeong, "Relationships among depression, acceptance of disability and coping skills in post-stroke elderly women", (Master's thesis), Cathholic University of Daegu, Daegu, (2011).

[32] E. J. Ryu, "Depression, self-efficacy and coping in patients with cancer", Journal Korean Acad Adult Nurs, vol. 13, no. 1, (2001), pp. 70-81.

[33] J. K. Tak, "The relations of coping strategies with individual characteristics, stressful events, and mental/physical Health: Multivariate analysis”, Korean J Heal Psych, vol. 2, no. 1, (1997), pp. 157-167.

[34] A. S. Darlington, D. W. Dippel, G. M. Ribbers, R. van Balen, J. Passchier and J. J. Busschbach, "Coping strategies as determinants of quality of life in stroke patients: a longitudinal study", Cerebrovasc Dis, vol. .23, no. 5, (2007), pp. 401-407.

[35] A. Zalewska, J. Miniszewska, Z. Juczynski, J. Chodkiewicx and A. Sysa-Jedrzejowska, "Acceptance of illness in psoriasis vulgaris Patient”, J Psychosom Res, vol. 56, no. 6, (2004), pp. 581-673.

\section{Authors}

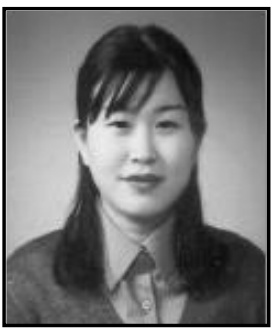

Sung-Hee Lee, she received the B.S. degree (2014) in occupational therapy from Gwangju University, Korea. She is an occupational therapist in the Department of Physical and Rehabilitation Medicine, Chonnam National University Bitgoeul Hospital. She present research is Sensory integration, Neurological occupational therapy and Cognitive rehabilitation.

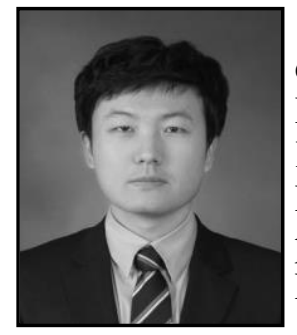

Sea-Hyun Bae, he received the B.S. degree (2011) and the M.S. degree (2014) in physical therapy from Dongshin University, Korea. $\mathrm{He}$ is received the Ph.D in the same area from Dongshin University, Korea in 2015. Currently, he is an Assistant Professor in the Department of Physical Therapy at Dongshin University, Korea. His present research is Neuro-therapeutic exercise and Human Engineering.

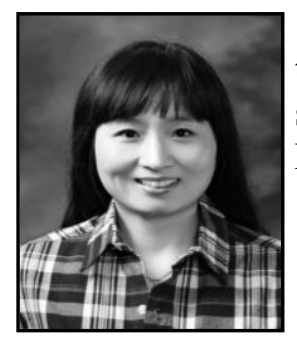

Jin-A Hwang, she received the B.S. degree (2013) in physical therapy from Dongshin University, Korea. She is Ph.D course in the same area from Dongshin University. She present research is Neuroscience, Therapeutic exercise. 




Kyung-Yoon Kim received the B.S. degree (2000) and the M.S. degree (2002) in physical therapy from Dongshin University, Korea. $\mathrm{He}$ is received the Ph.D in the same area from Dongshin University, Korea in 2007. Currently, he is an Associate Professor in the Department of Physical Therapy at Dongshin University, Korea. His present research is therapeutic exercise and biomechanics. 